\title{
施石灰和秸秆还田对双季稻产量和氮素吸收的互作效应
}

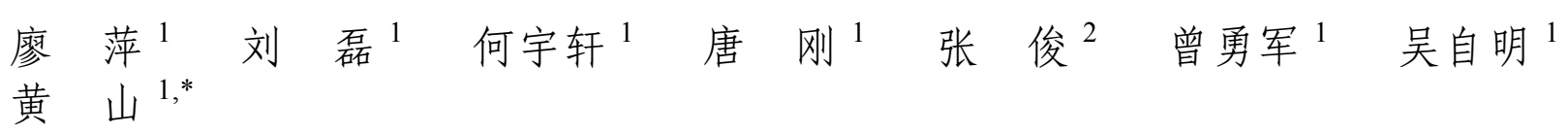

${ }^{1}$ 教育部和江西省作物生理生态与遗传育种重点实验室 / 江西农业大学, 江西南昌 $330045 ;{ }^{2}$ 中国农业科学院作物科学研究所, 北京
100081

摘 要: 红壤稻田面临土壤酸化和肥力偏低的双重挑战。施石灰和秸秆还田分别是稻田土壤酸化改良和培肥的有效 措施, 但二者的互作效应尚不清楚。本研究连续 4 年(2015-2018 年)在江西省开展施石灰和秸秆还田双因素田间定 位试验, 旨在探明施石灰和秸秆还田对红壤双季稻田水稻产量和氮素吸收的互作效应。结果表明, 施石灰和秸秆还田 均显著提高了早、晚稻的产量和氮素吸收，且二者具显著的协同促进效应。秸秆还田下，施石灰使早稻产量和氮素吸 收分别增加 $10.7 \%$ 和 $15.5 \%$; 而在秸秆不还田下，增幅仅分别为 $4.4 \%$ 和 $9.7 \%$ 。秸秆还田下，石灰使晚稻产量和氮素 吸收分别提高 $18.7 \%$ 和 $24.6 \%$; 但在秸秆不还田下，增幅则分别为 $10.5 \%$ 和 $5.7 \%$ 。施石灰对早、晚稻产量和氮素吸收 的促进效应随试验年限的增加而减弱。石灰对土壤 $\mathrm{pH}$ 值的提升效应随试验年限的延长显著降低。试验 4 年后，石灰 对土壤有机质和全氮含量均无显著影响; 秸秆还田显著提高了土壤有机质含量, 而对全氮含量无显著影响。因此, 秸 秆还田配施石灰能够协同实现双季稻增产、土壤酸化改良与培肥。本研究表明在此酸性的红壤双季稻田上每 4 年左 右施用一次石灰为宜。

关键词：土壤酸化; 秸秆还田; 石灰; 双季稻; 产量; 氮素吸收

\section{Interactive effects of liming and straw incorporation on yield and nitrogen uptake in a double rice cropping system}

\author{
LIAO Ping ${ }^{1}$, LIU Lei ${ }^{1}$, HE Yu-Xuan ${ }^{1}$, TANG Gang ${ }^{1}$, ZHANG Jun ${ }^{2}$, ZENG Yong-Jun ${ }^{1}$, WU Zi-Ming ${ }^{1}$, and \\ HUANG Shan ${ }^{1, *}$

\footnotetext{
${ }^{1}$ Ministry of Education and Jiangxi Key Laboratory of Crop Physiology, Ecology and Genetic Breeding, Jiangxi Agricultural University, Nanchang 330045, Jiangxi, China $;{ }^{2}$ Institute of Crop Sciences, Chinese Academy of Agricultural Sciences, Beijing 100081, China
}

\begin{abstract}
Soil acidification and low fertility limit crop productivity in red paddy soils. Liming and straw incorporation are effective practices to alleviate soil acidification and improve soil fertility, respectively, while their interaction is still unclear. A four-year field experiment was conducted in a double rice cropping system with red paddy soil in Jiangxi province to examine the interactive effect of liming and straw incorporation on rice yield and nitrogen (N) uptake from 2015 to 2018 . Either liming or straw incorporation increased grain yield and $\mathrm{N}$ uptake in both early and late rice seasons. Lime application increased yield and $\mathrm{N}$ uptake by $10.7 \%$ and $15.5 \%$ under straw incorporation, while by $4.4 \%$ and $9.7 \%$ with straw removal in the early rice season, respectively. In contrast, liming enhanced yield and $\mathrm{N}$ uptake by $18.7 \%$ and $24.6 \%$ in the straw-incorporated treatments in the late rice season, respectively, whereas only by $10.5 \%$ and $5.7 \%$ in the straw-removed treatments. The effect of liming on enhancing grain yield, $\mathrm{N}$ uptake and soil $\mathrm{pH}$ for both early and late rice diminished in the present of time. Neither soil organic matter nor total $\mathrm{N}$ content was significantly affected by liming after the four-year experiment. Straw incorporation significantly increased soil organic matter, but had no effect on total N. Therefore, limes should be applied along with straw incorporation to simultaneously increase double rice yield, alleviate soil acidification, and improve soil fertility on acidic paddies. Besides, our results suggest that
\end{abstract}

本研究由国家自然科学基金项目(31701383)和国家重点研发计划项目(2018YFD0301102)资助。

This work was supported by the National Natural Science Foundation of China (31701383) and the National Key Research and Development Program of China (2018YFD0301102).

*通信作者(Corresponding author): 黄山, E-mail: ecohs@126.com

第一作者联系方式: E-mail: 763979314@qq.com

Received (收稿日期): 2019-04-01; Accepted (接受日期): 2019-08-09; Published online (网络出版日期): 2019-09-03.

URL: http://kns.cnki.net/kcms/detail/11.1809.S.20190902.1810.010.html 
limes should be applied approximately every four years in the double rice cropping system with acidic red soil.

Keywords: soil acidification; straw incorporation; liming; double rice; grain yield; nitrogen uptake

全球近一半人口以稻米为主食, 中国是世界上 最大的水稻生产国, 稻米产量占全球总产量的 21.8\% (http://www.fao.org/faostat/en/\#data/QC)。南方 双季稻区光温水资源丰富, 是我国重要的稻作区域, 对保障我国粮食安全具有重要意义 (http://www. zzys.moa.gov.cn/ $)^{[1]}$, 但其土壤 $\mathrm{pH}$ 较低, 加之长期施 用氮肥, 稻田土壤酸化严重, 已经制约了水稻产量 的持续提升 ${ }^{[2-3]}$ 。

施用石灰是一种改良土壤酸化和提高作物产量 的有效措施 ${ }^{[4-5]}$ 。其作用主要表现为提高土壤 $\mathrm{pH}$ 值 和钙盐含量, 降低土壤 $\mathrm{Al}^{3+}$ 的毒害作用 ${ }^{[6]}$ 。适量施用 石灰能够提高土壤缓冲能力, 促进水稻根系生长及 其对土壤养分的吸收利用 ${ }^{[7]}$ 。还能够提高土壤微生 物数量和酶活性, 促进有机物的矿化速率 ${ }^{[8]}$ 。然而, 单施石灰虽对治理稻田土壤酸化效果显著, 但在提 升酸性土壤肥力方面作用有限 ${ }^{[4]}$ 。

由于双季稻区周年产量较高, 秸秆资源丰富, 是一种重要的土壤有机培肥资源 ${ }^{[9]}$ 。随着机械收获 的普及, 直接原位还田是目前最经济有效的秸秆资 源化利用方式 ${ }^{[10]}$ 。研究表明 ${ }^{[11-12]}$, 长期秸秆还田能 够提高水稻产量和改善土壤肥力。然而, 在短期内, 秸秆还田对水稻的增产效果不明显 ${ }^{[13-14]}$ 。主要是因 为秸秆碳氮比较高, 直接还田后短期内会引起微生 物对氮素的固定, 不利于水稻生长 ${ }^{[8,13,15]}$ 。特别是在 晚稻季, 由于前后茬时间紧张, 早稻秸秆还田后快速 腐解往往会抑制晚稻分臨 ${ }^{[14]}$ 。而且, 秸秆的碱度较低, 秸秆还田在缓解土壤酸化方面作用有限 ${ }^{[16-17]}$ 。因此, 我们假设, 石灰和秸秆配施在利用石灰改善土壤酸 化和促进有机物分解的同时, 能够缓解短期内秸秆 还田的不利影响并发挥其培肥地力的功能, 对水稻 生长产生协同促进作用。以往的研究主要侧重对石 灰或秸秆还田效应的单独分析, 对两者的互作效应 关注较少 ${ }^{[4,18]}$ 。我们在酸性的红壤性双季稻田上开展 石灰和秸秆还田两因素定位试验, 旨在明确二者对 水稻产量、氮素吸收和土壤性状的互作效应以及石 灰的有效作用年限, 为南方双季稻系统的持续增 产、土壤酸化改良和培肥提供科学依据。

\section{1 材料与方法}

\section{1 试验地概况}

江西省宜春市上高县泗溪镇曾家村 $\left(28^{\circ} 31^{\prime} \mathrm{N}\right.$, $\left.115^{\circ} 09^{\prime} \mathrm{E}\right)$ 。试验地属于典型的亚热带气候, 年平均 降雨量和气温分别为 $1650 \mathrm{~mm}$ 和 $17.5^{\circ} \mathrm{C}$ 。种植制 度为冬季休闲一早稻一晚稻。供试土壤为第四纪红色 黏土发育而成的水稻土, 试验前耕层 $0 \sim 15 \mathrm{~cm}$ 土壤

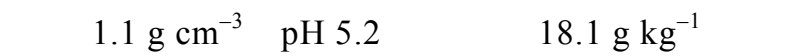
$1.1 \mathrm{~g} \mathrm{~kg}^{-1}$ 、全磷 $0.4 \mathrm{~g} \mathrm{~kg}^{-1}$ 、全钾 $3.9 \mathrm{~g} \mathrm{~kg}^{-1}$ 、碱解氮 $115.0 \mathrm{mg} \mathrm{kg}^{-1}$ 、有效磷 $15.9 \mathrm{mg} \mathrm{kg}^{-1}$ 、有效钾 $64.0 \mathrm{mg} \mathrm{kg}^{-1}$ 、 土壤黏粒含量 $(<0.002 \mathrm{~mm}) 17.0 \%$ 。

\section{2 试验设计}

采用二因素完全随机区组设计, 小区面积为 $25 \mathrm{~m}^{2}$ 。共设置 4 个处理, 分别为: 1)对照(CK), 不施 石灰、秸秆不还田；2)施用石灰处理(L), 仅在 2015 年早稻翻耕前施用一次, 施用量为 $2.1 \mathrm{t} \mathrm{hm}^{-2}[19]$, 秸 秆不还田; 3)秸秆还田处理(RS), 水稻收获后, 将秸 秆切成约 $10 \mathrm{~cm}$ 小段后均匀抛撒, 不施石灰; 4)秸秆 还田配施石灰处理 $(\mathrm{L}+\mathrm{RS})$, 石灰和秸秆施用量及施 用方式分别同 L 处理和 RS 处理。每个处理 3 次重复。 4 个处理的氮磷钾化肥施用量和施用方式相同。氮肥、 磷肥和钾肥早稻施用量分别为纯氮 $120 \mathrm{~kg} \mathrm{hm}^{-2}$ 、纯 磷 $33 \mathrm{~kg} \mathrm{hm}^{-2}$ 和纯钾 $62 \mathrm{~kg} \mathrm{hm}^{-2}$; 晚稻施用量分别为 纯氮 $150 \mathrm{~kg} \mathrm{hm}^{-2}$ 、纯磷 $33 \mathrm{~kg} \mathrm{hm}^{-2}$ 和纯钾 $62 \mathrm{~kg} \mathrm{hm}^{-2}$ 。 早晚稻均以尿素为氮肥, 基肥、分菜肥和穗肥施用 比例为 5：2：3; 以钙镁磷肥为磷肥，作基肥一次性 施用; 以氯化钾为钾肥, 基肥和穗肥施用比例为 5 : 5 。连续 4 年定位试验早稻品种均为常规籼稻中嘉早 17 , 晚稻品种均为杂交籼稻五优 308 。采用水育秧方 式, 2015-2018 年早稻播种日期分别为 3 月 22 日、 3 月 20 日、3 月 23 日和 3 月 22 日, 移栽日期分别 为 4 月 24 日、 4 月 21 日、 4 月 22 日和 4 月 16 日; 晚 稻播种日期分别为 6 月 24 日、 6 月 22 日、 6 月 27 日和 6 月 24 日, 移栽日期分别为 7 月 22 日、7 月 20 日、7 月 26 日和 7 月 20 日。早、晚稻的栽插密 度分别为 $13.2 \mathrm{~cm} \times 23.1 \mathrm{~cm}$ 和 $13.2 \mathrm{~cm} \times 26.4 \mathrm{~cm}$, 基 本苗分别为每穴 4 株和 2 株。采用人工插种和收获。 早、晚稻季田间水分管理均采用移栽后浅水, 分藍 末期排水晒田，复水后干湿交替直至收获前 1 周左 右断水。冬季休闲期田间水分自然排干。病虫草害 防控按照当地高产栽培模式进行。

\section{3 指标测定方法}

1.3.1 产量及其构成和生物量在水稻成熟期, 调查每个小区 120 萖计算有效穗, 按照平均数法从 
各小区取 5 萖水稻, 手工脱粒, 利用水漂法考察穗 粒结构。另取各小区 5 萖水稻, 将地上部植株从基 部剪除后洗净, 将茎鞘、叶和穗分开, 于 $105^{\circ} \mathrm{C}$ 杀青 $30 \mathrm{~min}$ 后, $70^{\circ} \mathrm{C}$ 烘干至恒重。从各小区收割 $10 \mathrm{~m}^{2}$ 水稻机械脱粒后称重, 并随机取 $1 \mathrm{~kg}$ 稻谷于 $70^{\circ} \mathrm{C}$ 烘 干测定含水量, 折合 $14 \%$ 标准含水量的水稻产量。

\subsection{2 氮素吸收将植株烘干称重后, 机械粉碎,} 过 $0.25 \mathrm{~mm}$ 篮。采用 Kjeltec 8400 全自动凯氏定氮仪 (福斯集团公司, 丹麦) 测定植株各器官氮素含量, 并 根据各器官干物质重和氮素含量计算地上部氮素吸 收总量。

1.3.3土壤性状收获晚稻后, 于各小区采用五 点法取 $0 \sim 15 \mathrm{~cm}$ 耕层土样, 自然风干后, 过 $2 \mathrm{~mm}$ 篮 保存, 待测相关土壤属性。采用 PHS-3C pH 测试仪(上 海仪电科学仪器股份有限公司, 中国)测定土壤 $\mathrm{pH}$ 值; 重铬酸钾容量法测定土壤有机质含量; Kjeltec 8400 全自动凯氏定氮仪(福斯集团公司, 丹麦)测定土壤全 氮含量 ${ }^{[19]}$ 。每年均测定土壤 $\mathrm{pH}$ 值, 而仅在 2018 年晚 稻收获后测定土壤有机质和全氮含量。

\section{4 统计分析}

采用 SPSS 18.0 软件(SPSS Inc., 美国)进行统计 分析, 于 $P<0.05$ 水平进行显著性检验。对于早稻和 晚稻产量及其构成、地上部氮素吸收量、周年产量、 周年氮素吸收和土壤 $\mathrm{pH}$ 值采用石灰 $(\mathrm{L}) 、$ 秸秆还田 $(\mathrm{RS})$ 和年份 $(\mathrm{Y})$ 三因素方差分析。对于 4 年总产量、

4 年总氮素吸收、土壤有机质和全氮含量采用 $\mathrm{L}$ 和 $\mathrm{RS}$ 二因素方差分析。

\section{2 结果与分析}

\section{1 施石灰和秸秆还田对早稻的影响}

施石灰和秸秆还田均显著提高早稻产量和氮素 吸收(表 1)。并且二者具显著互作效应。在秸秆还田 条件下, 施石灰使早稻产量和氮素吸收分别增加 $10.7 \%$ 和 $15.5 \%$; 在秸秆不还田条件下，增幅分别为 4.4\%和 9.7\% (图 1)。施石灰和试验年限对早稻产量 和氮素吸收具有显著互作效应。施石灰对早稻产量 和氮素吸收的促进效应在 2016 年最大, 之后增幅随 着试验年限的增加逐渐降低, 在 2018 年施石灰对早 稻产量和氮素吸收无显著影响。从产量构成来看, 施石灰显著提高早稻的有效穗数和每穗粒数, 对结 实率和千粒重无显著性影响。秸秆还田亦显著提高 了早稻的有效穗数和每穗粒数, 但显著降低了结实 率。施石灰和秸秆还田对早稻各产量构成因素均无 显著的互作效应。

\section{2 施石灰和秸秆还田对双季晚稻的影响}

与早稻结果相似, 施石灰和秸秆还田均显著提高 晚稻产量和氮素吸收, 且二者具显著互作效应(表 2)。 在秸秆还田条件下, 施石灰使晚稻产量和氮素吸收 分别提高 $18.7 \%$ 和 $24.6 \%$; 而在秸秆不还田条件下, 增幅分别为 $10.5 \%$ 和 $5.7 \%$ (图 2)。另外, 施石灰和试 验年限对晚稻产量和氮素吸收也具有显著互作效 应。施用石灰对晚稻产量的促进效应在 2015 年最大 $(+26.7 \%)$, 氮素吸收在 2016 年增幅最大 $(+30.7 \%)$, 之后增幅逐渐降低, 在 2018 年施石灰对晚稻产量和

表 1 施石灰和秸秆还田对双季早稻产量及其构成、氮素吸收的影响 $(F$ 值)

Table 1 Effects of liming and straw incorporation on grain yield and its components, and $\mathrm{N}$ uptake in early rice ( $F$-values)

\begin{tabular}{|c|c|c|c|c|c|c|}
\hline $\begin{array}{c}\text { 变异来源 } \\
\text { Source of variations }\end{array}$ & $\begin{array}{c}\text { 有效穗 } \\
\text { Effective panicle }\end{array}$ & $\begin{array}{c}\text { 每穗粒数 } \\
\text { Spikelets per } \\
\text { panicle }\end{array}$ & $\begin{array}{c}\text { 结实率 } \\
\text { Seed-setting } \\
\text { rate }\end{array}$ & $\begin{array}{c}\text { 千粒重 } \\
\text { 1000-grain } \\
\text { weight } \\
\end{array}$ & $\begin{array}{c}\text { 产量 } \\
\text { Grain yield }\end{array}$ & $\begin{array}{l}\text { 氮素吸收 } \\
\text { N uptake }\end{array}$ \\
\hline 石灰 Liming (L) & $16.0^{* *}$ & $20.1^{* *}$ & 0.2 & 1.3 & $33.5^{* *}$ & $48.0^{* *}$ \\
\hline 秸秆还田 Straw incorporation (RS) & $154.2^{* *}$ & $15.6^{* *}$ & $7.8^{* *}$ & 0 & $111.3^{* *}$ & $133.5^{* *}$ \\
\hline 年份 Year (Y) & $100.0^{* *}$ & $7.9^{* *}$ & $87.8^{* *}$ & $11.8^{* *}$ & $64.1^{* *}$ & $111.0^{* *}$ \\
\hline 石灰 $\times$ 秸秆还田 $\mathrm{L} \times \mathrm{RS}$ & 3.0 & 1.0 & 0.9 & 0.6 & $7.2^{*}$ & $4.8^{*}$ \\
\hline 石灰 $\times$ 年份 $\mathrm{L} \times \mathrm{Y}$ & 2.1 & $3.4^{*}$ & $3.6^{*}$ & 0.3 & $4.6^{* *}$ & $5.4^{* *}$ \\
\hline 秸秆还田 $\times$ 年份 $\mathrm{RS} \times \mathrm{Y}$ & 1.4 & $4.8^{* *}$ & 1.6 & 1.1 & $4.7^{* *}$ & $5.2^{* *}$ \\
\hline 石灰×秸秆还田×年份 $\mathrm{L} \times \mathrm{RS} \times \mathrm{Y}$ & 0.2 & 0.5 & 0.5 & 0.3 & 1.2 & 1.6 \\
\hline
\end{tabular}

"和"*分别表示在 0.05 和 0.01 概率水平下差异显著。

${ }^{*}$ and ${ }^{* *}$ : significant at the 0.05 and 0.01 probability levels, respectively. 

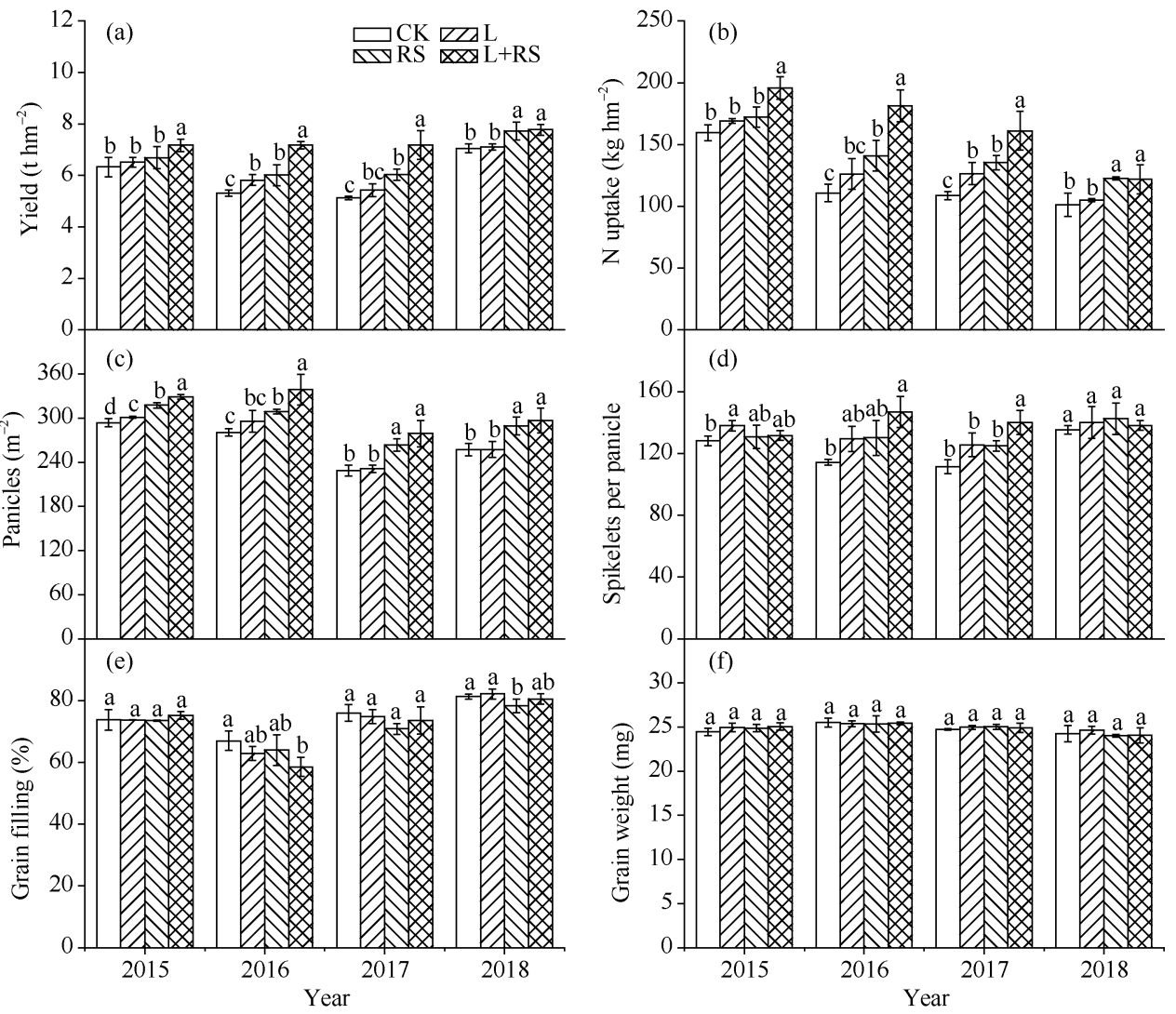

图 1 施石灰和秸秆还田对双季早稻产量及其构成、氮素吸收的影响(2015-2018)

Fig. 1 Effects of liming and straw incorporation on grain yield and its components, and $N$ uptake in early rice (2015-2018)

$\mathrm{CK} 、 \mathrm{~L} 、 \mathrm{RS}$ 和 L+RS 分别表示对照、单施石灰、秸秆还田、秸秆还田配施石灰。误差线表示平均值的标准差 $(n=3)$ 。同一年份标的 不同小写字母的柱值在不同处理间差异显著 $(P<0.05)$ 。

CK, L, RS, and L+RS mean control, liming, straw incorporation, and straw incorporation with liming, respectively. Error bars represent the standard deviation of the mean $(n=3)$. Bars superscripted by different letters are significantly different at $P<0.05$ in the same year.

氮素吸收无显著影响。施石灰显著提高了晚稻的有 效穗数和每穗粒数，而对结实率无显著性影响。秸 秆还田显著提高了晚稻的每穗粒数, 对有效穗数和 千粒重均无显著影响, 但显著降低晚稻结实率。施 石灰和秸秆还田对晚稻有效穗数具有显著的协同促
进效应。施石灰和和秆还田对晚稻有效穗数和氮素 吸收正的互作效应随试验年限的增加表现降低趋势 $(\mathrm{L} \times \mathrm{RS} \times \mathrm{Y}: P<0.01)$ 。在秸秆还田条件下，施用石灰 对晚稻氮素吸收的促进效应在 2016 年最大(46.7\%), 有效穗数在 2015 年增幅最大, 达 $27.3 \%$ (图 2)。

表 2 施石灰和秸秆还田对双季晚稻产量及其构成、氮素吸收的影响 $(\boldsymbol{F}$ 值)

Table 2 Effects of liming and straw incorporation on grain yield and its components, and $\mathrm{N}$ uptake in late rice $(F$-values)

\begin{tabular}{|c|c|c|c|c|c|c|}
\hline $\begin{array}{c}\text { 变异来源 } \\
\text { Source of variations }\end{array}$ & $\begin{array}{l}\text { 有效穗 } \\
\text { Effective } \\
\text { panicle }\end{array}$ & $\begin{array}{c}\text { 每穗粒数 } \\
\text { Spikelets per } \\
\text { panicle }\end{array}$ & $\begin{array}{c}\text { 结实率 } \\
\text { Seed-setting rate }\end{array}$ & $\begin{array}{c}\text { 千粒重 } \\
\text { 1000-grain } \\
\text { weight }\end{array}$ & $\begin{array}{c}\text { 产量 } \\
\text { Grain yield }\end{array}$ & $\begin{array}{l}\text { 氮素吸收 } \\
\mathrm{N} \text { uptake }\end{array}$ \\
\hline 石灰 Liming (L) & $94.3^{* *}$ & $45.2^{* *}$ & 1.1 & $9.7^{* *}$ & $125.7^{* *}$ & $93.1^{* *}$ \\
\hline 秸秆还田 Straw incorporation (RS) & 0.9 & $69.5^{* *}$ & $22.2^{* *}$ & 0.4 & $18.4^{* *}$ & $65.7^{* *}$ \\
\hline 年份 Year (Y) & $67.8^{* *}$ & $15.6^{* *}$ & $37.7^{* *}$ & $11.5^{* *}$ & $49.4^{* *}$ & $26.1^{* *}$ \\
\hline 石灰 $\times$ 秸秆还田 $\mathrm{L} \times \mathrm{RS}$ & $25.9^{* *}$ & 0.4 & 0.6 & 0.3 & $10.4^{* *}$ & $38.0^{* *}$ \\
\hline 石灰 $\times$ 年份 $\mathrm{L} \times \mathrm{Y}$ & $10.3^{* *}$ & $5.5^{* *}$ & 2.2 & 1.1 & $20.8^{* *}$ & $15.2^{* *}$ \\
\hline 秸秆还田 $\times$ 年份 $\mathrm{RS} \times \mathrm{Y}$ & 2.3 & $3.6^{*}$ & $7.5^{* *}$ & 1.9 & 0.7 & $10.3^{* *}$ \\
\hline 石灰 $\times$ 秸秆还田 $\times$ 年份 $\mathrm{L} \times \mathrm{RS} \times \mathrm{Y}$ & $6.5^{* *}$ & 0.1 & 0.7 & 0.2 & 1.2 & $6.1^{* *}$ \\
\hline
\end{tabular}

"和“分别表示在 0.05 和 0.01 概率水平下差异显著。

" and ${ }^{* *}$ significant at the 0.05 and 0.01 probability levels, respectively. 

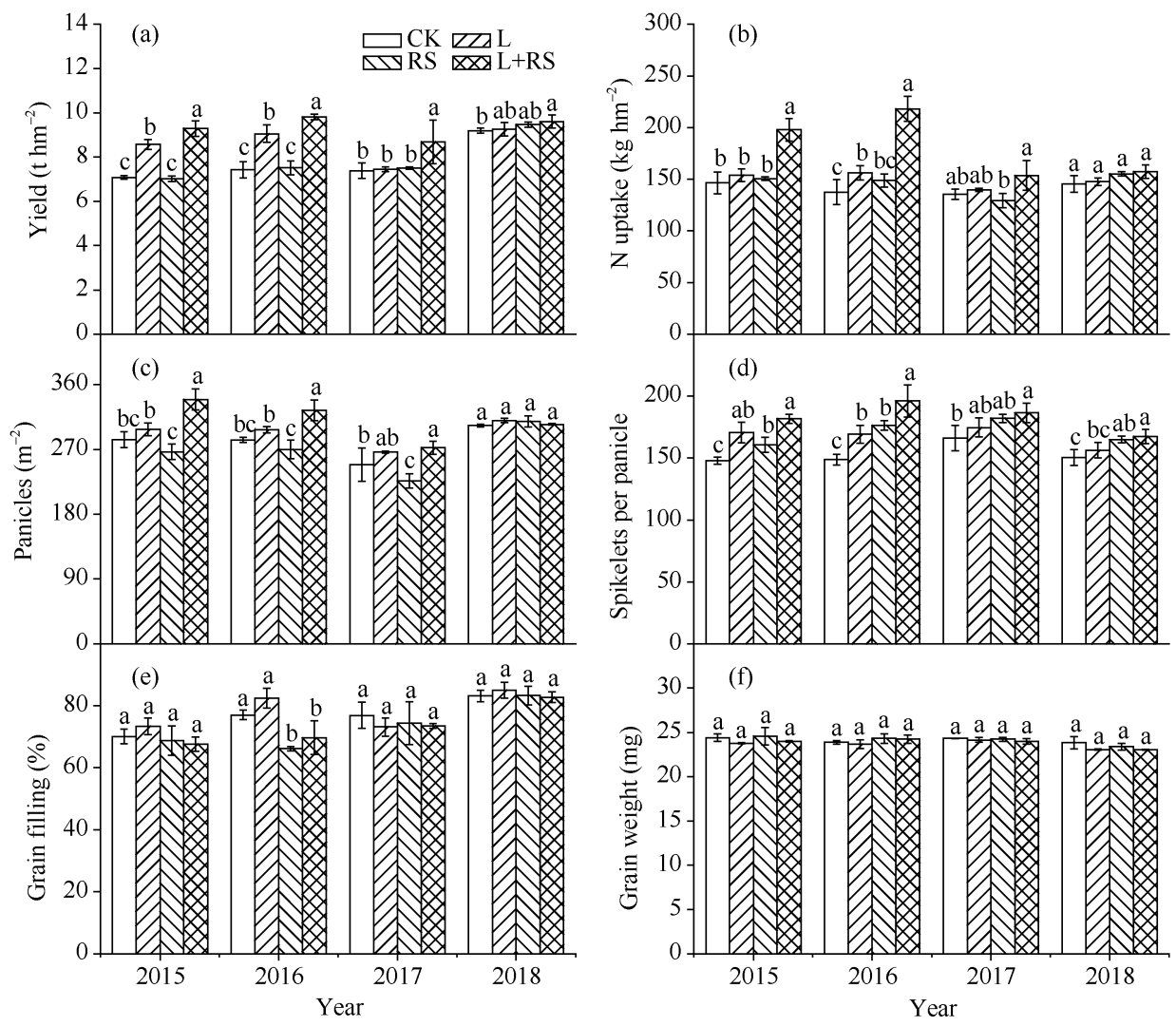

图 2 石灰和秸秆还田对双季晚稻产量及其构成、氮素吸收的影响(2015-2018)

Fig. 2 Effects of liming and straw incorporation on grain yield and its components, and $N$ uptake in late rice (2015-2018) 缩写同图 1。误差线表示平均值的标准差 $(n=3)$ 。同一年份标的不同小写字母的柱值在不同处理间差异显著 $(P<0.05)$ 。

Abbreviations are the same as those given in Fig. 1. Error bars represent the standard deviation of the mean $(n=3)$. Bars superscripted by different letters are significantly different at $P<0.05$ in the same year.

2.3 施石灰和秸秆还田对双季稻周年产量和氮 素吸收的影响

施石灰和秸秆还田均显著提高周年产量和周 年氮素吸收，且二者具显著互作效应(图 3-a, b)。在 秸秆还田条件下，施石灰使周年产量和周年氮素吸 收分别提高 $15.0 \%$ 和 $20.1 \%$; 而在秸秆不还田条件 下，增幅分别为 $7.9 \%$ 和 $7.5 \%$ 。施石灰和试验年限 对周年产量和周年氮素吸收均具有显著互作效应。 施石灰对周年产量和周年氮素吸收的促进效应在 2016 年最大, 之后增幅随着试验年限的增加逐渐 降低, 在 2018 年施石灰对周年产量和周年氮素吸 收无显著影响。

施石灰和秸秆还田均显著提高 4 年的总产量和 总氮素吸收, 且二者具显著互作效应(图 3-c, d)。在 秸秆还田条件下, 施石灰使总产量和总氮素吸收分 别提高 $15.0 \%$ 和 $20.1 \%$; 而在秸秆不还田条件下, 增 幅分别为 $7.9 \%$ 和 $7.5 \%$ 。

\section{4 施石灰和秸秆还田对土壤 $\mathrm{pH}$ 值的影响} 施石灰和秸秆还田均显著提高土壤 $\mathrm{pH}$ 值, 但 无显著互作效应(图 4)。施石灰与试验年限对土壤 $\mathrm{pH}$ 值有显著的互作效应。随着试验年限的增加, 施石 灰对土壤 $\mathrm{pH}$ 值的正效应减弱, 到 2018 年 4 个处理 间无显著差异。

2.5 施石灰和秸秆还田对土壤有机质和全氮含 量的影响

试验进行 4 年后, 施石灰对土壤有机质无显著 影响, 而秸秆还田显著增加了土壤有机质(图 5-a)。 施石灰和秸秆还田对土壤全氮均无显著影响(图 5-b), 且对土壤有机质和全氮含量均无显著的互作效应。

\section{3 讨论}

3.1 施石灰和秸秆还田对双季稻产量和氮素吸 收的互作效应

与前人研究一致, 秸秆还田能够显著提高双季 

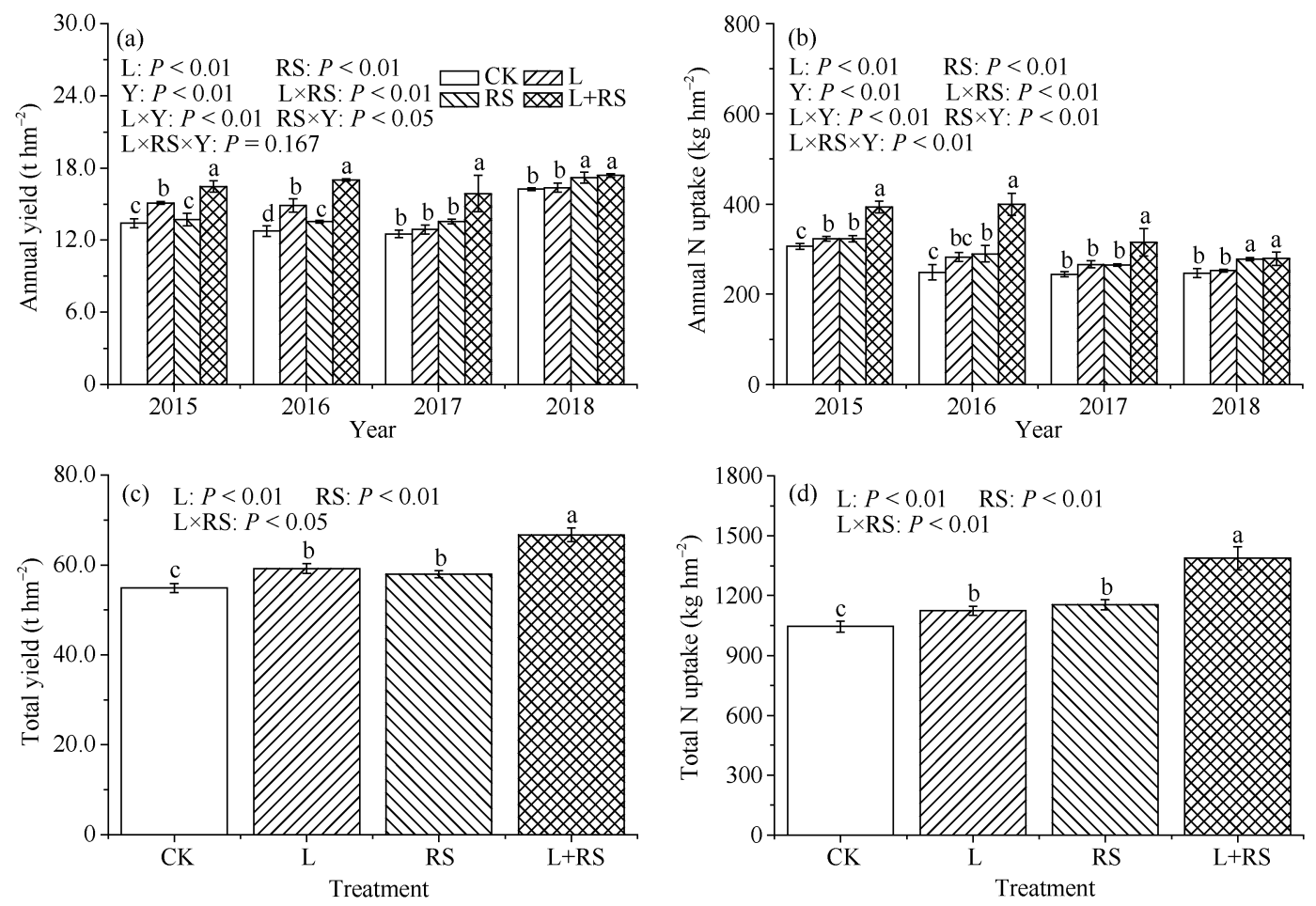

图 3 施石灰和秸秆还田对双季稻周年产量(a)、周年氮素吸收(b)、4 年总产量(c)和总氮素吸收(d)的影响

Fig. 3 Effects of liming and straw incorporation on annual yield (a), annual $N$ uptake (b), total yield (c), and total $N$ uptake (d) over the 4-year

缩写同图 1。误差线表示平均值的标准差 $(n=3)$ 。同一年份标的不同小写字母的柱值在不同处理间差异显著 $(P<0.05)$ 。

Abbreviations are the same as those given in Fig. 1. Error bars represent the standard deviation of the mean $(n=3)$. Bars superscripted by different letters are significantly different at $P<0.05$ in the same year.

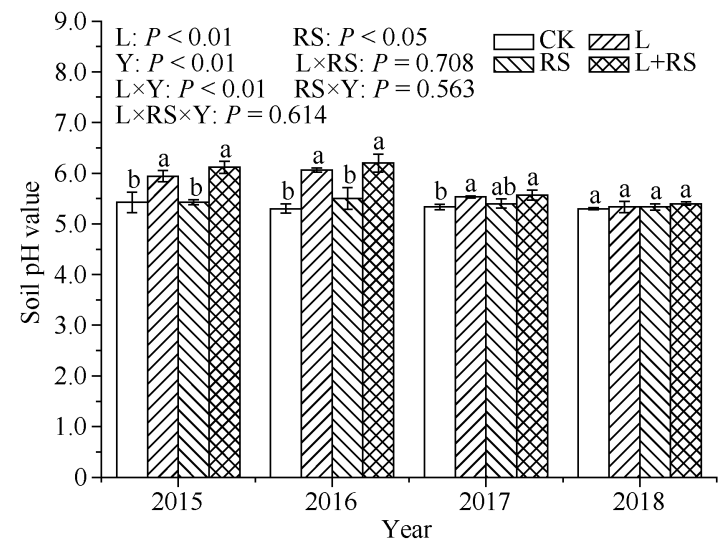

图 4 施石灰和秸秆还田对土壤 $\mathrm{pH}$ 值的影响(2015-2018)

Fig. 4 Effects of liming and straw incorporation on soil pH (2015-2018)

缩写同图 1。误差线表示平均值的标准差 $(n=3)$ 。同一年份标的 不同小写字母的柱值在不同处理间差异显著 $(P<0.05)$ 。

Abbreviations are the same as those given in Fig. 1. Error bars represent the standard deviation of the mean $(n=3)$. Bars superscripted by different letters are significantly different at $P<0.05$ in the same year.

早稻的产量和氮素吸收 ${ }^{[20]}$ 。原因主要是: (1)双季稻 系统较长的冬闲期有利于晚稻秸秆还田后的腐解矿 化 ${ }^{[8]}$ 。本研究也表明, 晚稻秸秆还田显著提高了第 2
年早稻的有效穗数，说明晚稻秸秆还田并不会导致 氮素固定和抑制早稻的分覧。(2)秸秆自身氮素以及 其他营养元素的矿化分解能够提高养分供给 ${ }^{[14,21]}$ 。 (3)秸秆还田能够改善土壤结构，促进根系发育及其 对土壤养分的吸取 ${ }^{[22-23]}$ 。此外, 秸秆为土壤微生物 提供了大量的碳源，提高了土壤微生物的数量和活 性 $^{[8,24]}$ 。然而, 与我们的结果不同, 有研究表明 ${ }^{[13-14]}$, 秸秆还田对双季晚稻无显著增产效应。主要是因为, 在双季稻系统早稻秸秆还田到晚稻秧苗移栽仅间隔 $10 \mathrm{~d}$ 左右, 加之气温较高, 大量高碳氮比秸秆的快 速腐解可能会导致微生物对土壤氮素的固定、水稻 前期根系活力下降，从而抑制水稻分藍，最终影响 水稻穗数 ${ }^{[8,14,25]}$ 。与前人研究结果相似, 本研究也发 现秸秆还田导致 2015-2017 年晚稻有效穗数下降 (图 2-c)，但是晚稻产量却显著增加(表 2)。可能是虽 然秸秆还田降低了晚稻有效穗数, 但土壤微生物前 期固定的氮素之后又被逐渐释放，促进了后期水稻 的穗分化、光合作用和灌浆速率，从而提高了每穗 粒数和产量 ${ }^{[8]}$ 。另外, 笔者推测, 稻田土壤肥力的差 异以及不同品种的生长发育和需肥特性不同也可能 

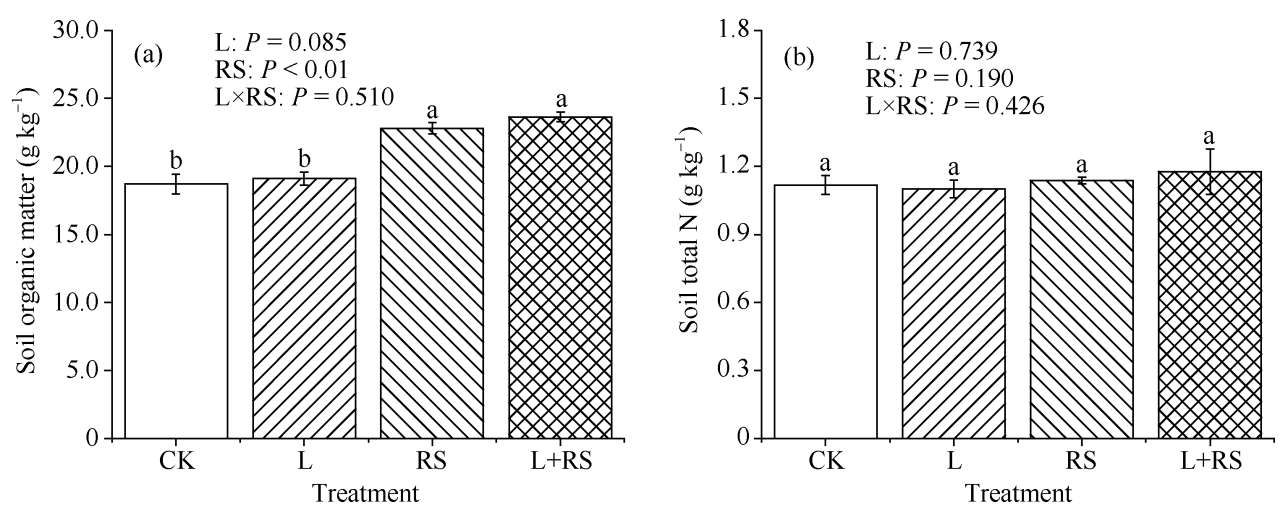

图 5 施石灰和秸秆还田对土壤有机质(a)和全氮(b)含量的影响(2018 年)

Fig. 5 Effects of liming and straw incorporation on soil organic matter (a) and total $\mathbf{N}$ content (b) (2018)

缩写同图 1。误差线表示平均值的标准差 $(n=3)$ 。同一年份标的不同小写字母的柱值在不同处理间差异显著 $(P<0.05)$ 。

Abbreviations are the same as those given in Fig.1. Error bars represent the standard deviation of the mean $(n=3)$. Bars superscripted by different letters are significantly different at $P<0.05$ in the same year.

是导致早稻秸秆还田对晚稻产量效应不一致的原 因。有研究表明 ${ }^{[26]}$, 秸秆还田在低肥力土壤上对土 壤有机质含量提升效果更显著, 有利于水稻增产。

本研究表明, 在酸性稻田上施用石灰能够显著 提高早、晚稻的产量和氮素吸收, 且和秸秆还田具 有显著的协同促进作用，这与我们的假设一致。施 石灰和秸秆还田对早稻产量正的互作效应主要是由 于二者协同促进了地上部氮素吸收(表 1)。这有利于 促进光合作用和同化物向籽粒的转运, 增加水稻产 量 ${ }^{[8,27]}$ 。而晚稻正的互作效应主要是由于施石灰和秸 秆还田对有效穗数和氮素吸收具有显著的协同促进 效应(表 2)。为什么秸秆还田配施石灰能显著促进水 稻氮素吸收? 主要是因为石灰能够提高土壤碳氮代 谢相关的酶活性, 提高有机调落物和土壤有机质的

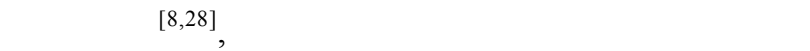
固定, 进而促进水稻的氮素吸收和生长以及产量形 成。特别是在晚稻季, 施石灰缓解了早稻秸秆还田 对晚稻前期分菜的不利影响, 因此施石灰和秸秆还 田对晚稻有效穗数具有正的互作效应。

本研究表明，施石灰和秸秆还田协同促进双季 稻氮素吸收, 但试验 4 年后土壤全氮含量无显著变 化。原因可能是土壤的基础氮素库容较大, 短期内 水稻对土壤氮库的影响尚未显现, 需要更长时间才 能探测出各处理土壤全氮含量的差异。但可以推测, 如果石灰施用下水稻氮素吸收的增加主要是来自肥 料氮(化肥氮或稻草氮), 则石灰能够提高氮肥利用 效率、降低环境污染; 如果是土壤氮, 则需要关注土 壤氮库的平衡和地力的维持。因此, 下一步研究需 要采用 ${ }^{15} \mathrm{~N}$ 交叉标记肥料氮和秸秆氮, 以揭示石灰
施用条件下水稻氮素吸收的来源 ${ }^{[15]}$ 。另外, 试验进 行 4 年后, 秸秆还田显著提高了土壤有机质含量, 但在 2018 年, L、RS 和 L+RS 处理间晚稻产量无显 著差异。其一, 随着试验年限的延长, 石灰改良土壤 酸化的效果在逐渐减弱, 导致其促进有机物矿化的 效果下降 ${ }^{[28]}$ 。其二, 秸秆还田在晚稻季对水稻生长 的负效应大于早稻季, 主要是由于早稻季的秸秆腐 解抑制了晚稻的前期分臨 ${ }^{[14]}$ 。最后, 秸秆还田虽然 能够显著提高土壤有机质, 但对水稻产量的影响还 受其他因素的共同作用，如秸秆的腐解程度、氮素 的有效性等 ${ }^{[29]}$ 。因此, 可能需要更长时间的秸秆还 田对土壤培肥的效应才能体现在双季晚稻产量的 增加。

\section{2 石灰的作用年限}

本研究表明, 施石灰和试验年限对双季早、晚 稻产量和氮素吸收具有显著互作效应, 早、晚稻产 量分别在 2016 年和 2015 年增幅最大(图 1-a, 图 2-a), 氮素吸收均在 2016 年增幅最大(图 1-b, 图 2-b), 之 后增幅逐渐降低。有研究表明 ${ }^{[18]}$, 随着年限的增加, 石灰改良后的酸化土壤容易出现反酸现象。本研究 也发现相似结果, 石灰改良土壤酸化的效果逐渐减 弱, 且试验第 4 年(2018 年)对土壤 $\mathrm{pH}$ 值无显著影响 (图 4)。当石灰对土壤 $\mathrm{pH}$ 值的正效应减弱时, 石灰 对有机物矿化的促进效果可能也会随之降低，从而 降低养分的释放速率，减弱其对水稻产量和氮素吸 收的促进效应 ${ }^{[18,28]}$ 。到 2018 年施石灰对早、晚稻产 量和氮素吸收均无显著影响。同时, 三因素方差分 析表明, 施石灰和秸秆还田对晚稻氮素吸收的协同 促进效应随试验年限的增加也整体表现降低趋势。 
因此，随着化肥氮的持续施用，土壤 $\mathrm{H}^{+}$会不断产生 中和石灰的碱性, 土壤 $\mathrm{pH}$ 也会随之回落。本研究表 明，在此酸性的红壤稻田每 4 年左右施用一次石灰 为宜。但是, 应该指出, 不同的田块土壤属性不同、 初始土壤 $\mathrm{pH}$ 值以及施氮量和产量水平也不同, 导 致其对石灰的需要量以及石灰的有效作用年限有所 差异 ${ }^{[30-32]}$ 。因此，应因地制宜根据水稻产量和土壤 酸度的响应确定石灰的再次施用时间 ${ }^{[18,32]}$ 。

\section{4 结论}

施石灰和秸秆还田能够协同提高双季稻产量, 主要是因为二者协同促进了水稻的氮素吸收。试验 4 年后, 施石灰对土壤有机质含量无显著性影响, 而 秸秆还田显著提高土壤有机质含量。因此, 秸秆还 田的同时配施石灰不仅能够提高双季稻产量, 而且 能够改良土壤酸化和培肥地力。石灰对稻田土壤酸 化的改良效果到第 4 年已经不显著。对酸化的红壤 稻田每 4 年左右施用一次石灰为宜。但是, 石灰和 秸秆还田对双季稻产量的协同促进效应是否能够维 持, 且石灰和秸秆配施对土壤的长期培肥效果均需 持续监测。

\section{References}

[1] Liu S L, Pu C, Ren Y X, Zhao X L, Zhao X, Chen F, Xiao X P, Zhang $\mathrm{H} \mathrm{L}$. Yield variation of double-rice in response to climate change in Southern China. Eur J Agron, 2016, 81: 161-168.

[2] Guo J H, Liu X J, Zhang Y, Shen J L, Han W X, Zhang W F, Christie P, Goulding K W, Zhang F S. Significant acidification in major Chinese croplands. Science, 2010, 327: 1008-1010.

[3] Miao Y X, Stewart B A, Zhang F S. Long-term experiments for sustainable nutrient management in China: a review. Agron Sustain Dev, 2011, 31: 397-414.

[4] 徐仁扣, 李九玉, 周世伟, 徐明岗, 沈仁芳. 我国农田土壤酸 化调控的科学问题与技术措施. 中国科学院院刊, 2018, 33: 160-167.

Xu R K, Li J Y, Zhou S W, Xu M G, Shen R F. Scientific issues and controlling strategies of soil acidification of croplands in China. China Acad J Electr Publish House, 2018, 33: 160-167 (in Chinese with English abstract).

[5] Holland J E, Bennett A E, Newton A C, White P J, McKenzie B M, George T S, Pakeman R J, Bailey J S, Fornara D A, Hayes R C. Liming impacts on soils, crops and biodiversity in the UK: a review. Sci Total Environ, 2018, 610: 316-332.

[6] Jiang Y, Liao P, van Gestel N, Sun Y N, Zeng Y J, Huang S, Zhang W J, van Groenigen K J. Lime application lowers the global warming potential of a double rice cropping system. Geoderma, 2018, 325: 1-8.

[7] Ai C, Liang G Q, Sun J W, He P, Tang S H, Yang S H, Zhou W, Wang X B. The alleviation of acid soil stress in rice by inorganic or organic ameliorants is associated with changes in soil enzyme activity and microbial community composition. Biol Fert Soils, 2015, 51: 465-477.

[8] Liao P, Huang S, van Gestel N, Zeng Y J, Wu Z M, van Groenigen $\mathrm{K}$ J. Liming and straw retention interact to increase nitrogen uptake and grain yield in a double rice-cropping system. Field Crops Res, 2018, 216: 217-224.

[9] Wang B, Shen X, Chen S, Bai Y C, Yang G, Zhu J P, Shu J C, Xue Z T. Distribution characteristics, resource utilization and popularizing demonstration of crop straw in Southwest China: a comprehensive evaluation. Ecol Indic, 2018, 93: 998-1004.

[10] 张国, 逯非, 赵红, 杨广斌, 王效科, 欧阳志云. 我国农作物 秸秆资源化利用现状及农户对秸秆还田的认知态度. 农业环 境科学学报, 2017, 36: 981-988.

Zhang G, Lu F, Zhao H, Yang G B, Wang X K, Ou-Yang Z Y. Residue usage and farmers' recognition and attitude toward residue retention in China's croplands. J Agro-Environ Sci, 2017, 36: 981-988 (in Chinese with English abstract).

[11] Li H, Dai M W, Dai S L, Dong X J. Current status and environment impact of direct straw return in China's cropland-A review. Ecotox Environ Safe, 2018, 159: 193-300.

[12] Han X, Xu C, Dungait J A, Bol R, Wang X J, Wu W L, Meng F Q. Straw incorporation increases crop yield and soil organic carbon sequestration but varies under different natural conditions and farming practices in China: a system analysis. Biogeosciences, 2018, 15: 1933-1946.

[13] Singh B, Shan Y H, Johnson-Beebout S E, Singh Y, Buresh R J. Crop residue management for lowland rice-based cropping systems in Asia. Adv Agron, 2008, 98: 117-199.

[14] 曾研华, 吴建富, 曾勇军, 范呈根, 谭雪明, 潘晓华, 石庆华. 机收稻草全量还田减施化肥对双季晚稻养分吸收利用及产量 的影响. 作物学报, 2018, 44: 454-462.

Zeng Y H, Wu J F, Zeng Y J, Fan C G, Tan X M, Pan X H, Shi Q $H$. Effects of straw incorporation with reducing chemical fertilizers on nutrient absorption and utilization and grain yield of double-cropping late rice under mechanical harvest. Acta Agron Sin, 2018, 44: 454-462 (in Chinese with English abstract).

[15] Pan F F, Yu W T, Ma Q, Zhou H, Jiang C M, Xu Y G, Ren J F. Influence of ${ }^{15} \mathrm{~N}$-labeled ammonium sulfate and straw on nitrogen retention and supply in different fertility soils. Biol Fert Soils, 2017, 53: 303-313.

[16] 孟红旗, 刘景, 徐明岗, 吕家珑, 周宝库, 彭畅, 石孝均, 黄庆 海, 王伯仁. 长期施肥下我国典型农田耕层土壤的 $\mathrm{pH}$ 演变. 土壤学报, 2013, 50: 1109-1116.

Meng H Q, Liu J, Xu M G, Lyu J L, Zhou B K, Peng C, Shi X J, Huang Q H, Wang B R. Evolution of pH in top soils of typical Chinese croplands under long-term fertilization. Acta Pedol Sin, 2013, 50: 1109-1116 (in Chinese with English abstract).

[17] 孟红旗, 吕家珑, 徐明岗, 蔡泽江, 王伯仁. 有机肥的碱度及 其减缓土壤酸化的机制. 植物营养与肥料学报, 2012, 18: 1153-1160.

Meng H Q, Lyu J L, Xu M G, Cai Z J, Wang B R. Alkalinity of organic manure and its mechanism for mitigating soil acidification. Plant Nutr Fert Sci, 2012, 18: 1153-1160 (in Chinese with English abstract).

[18] Goulding K W T. Soil acidification and the importance of liming agricultural soils with particular reference to the United Kingdom. 
Soil Use Manage, 2016, 32: 390-399.

[19] 鲍士旦. 土壤农化分析. 北京: 农业出版社, 2006.

Bao S D. Soil and Agricultural Chemistry Analysis. Beijing: China Agriculture Press, 2006 (in Chinese).

[20] 曾研华, 范呈根, 吴建富, 曾勇军, 周春火, 谭雪明, 潘晓华, 石庆华. 等养分条件下稻草还田替代双季早稻氮钾肥比例的 研究. 植物营养与肥料学报, 2017, 23: 658-668.

Zeng Y H, Fan C G, Wu J F, Zeng Y J, Zhou C H, Tan X M, Pan $\mathrm{X} \mathrm{H}$, Shi Q H. Replacement ratio of nitrogen and potassium fertilizer by straw incorporation in early rice under the same nitrogen, phosphorus and potassium input. Plant Nutr Fert Sci, 2017, 23: 658-668 (in Chinese with English abstract).

[21] 孙凯, 刘振, 胡恒宇, 李耕, 刘文涛, 杨柳, 宁堂原, 王彦玲. 有机培肥与轮耕方式对夏玉米田土壤碳氮和产量的影响. 作 物学报, 2019, 45: 401-410.

Sun K, Liu Z, Hu H Y, Li G, Liu W T, Yang L, Ning T Y, Wang Y L. Effect of organic fertilizer and rotational tillage practices on soil carbon and nitrogen and maize yield in wheat-maize cropping system. Acta Agron Sin, 2019, 45: 401-410 (in Chinese with English abstract).

[22] 李昊昱, 孟兆良, 庞党伟, 陈金, 侯永坤, 崔海兴, 金敏, 王振 林, 李勇. 周年秸秆还田对农田土壤固碳及冬小麦-夏玉米产 量的影响. 作物学报, 2019, 45: 893-903.

Li H Y, Meng Z L, Pang D W, Chen J, Hou Y K, Cui H X, Jin M, Wang Z L, Li Y. Effect of annual straw return model on soil carbon sequestration and crop yields in winter wheat-summer maize rotation farmland. Acta Agron Sin, 2019, 45: 893-903 (in Chinese with English abstract).

[23] 陈玉章, 柴守胥, 程宏波, 柴雨藏, 杨长刚, 谭凯敏, 常磊. 秸 秆还田结合秋覆膜对旱地冬小麦耗水特性和产量的影响. 作 物学报, 2019, 45: 256-266.

Chen Y Z, Chai S X, Cheng H B, Chai Y W, Yang C G, Tan K M, Chang L. Effects of straw-incorporation combined with autumn plastic mulching on soil water consumption characteristics and winter wheat yield in arid farming areas. Acta Agron Sin, 2019, 45: 256-266 (in Chinese with English abstract).

[24] 曾研华, 吴建富, 潘晓华, 石庆华, 朱德峰. 稻草原位还田对 双季稻田土壤理化与生物学性状的影响. 水土保持学报, 2013, 27(3): 150-155.

Zeng Y H, Wu J F, Pan X H, Shi Q H, Zhu D F. Effects of rice straw incorporation on soil physical, chemical and biological properties in double cropping paddy fields. J Soil Water Conserv, 2013, 27(3): 150-155 (in Chinese with English abstract).

[25] Xu Y Z, Nie L X, Buresh R J, Huang J L, Cui K H, Xu B, Gong
W H, Peng S B. Agronomic performance of late-season rice under different tillage, straw, and nitrogen management. Field Crops Res, 2010, 115: 79-84.

[26] Zhao Y C, Wang M Y, Hu S J, Zhang X D, Ou-Yang Z, Zhang G L, Huang B, Zhao S W, Wu J S, Xie D T, Zhu B, Yu D S, Pan X Z, $\mathrm{Xu} S \mathrm{X}$, Shi X Z. Economics- and policy-driven organic carbon input enhancement dominates soil organic carbon accumulation in Chinese croplands. Proc Natl Acad Sci USA, 2018, 115: 4045-4050.

[27] 唐海明, 肖小平, 李超, 汤文光, 郭立君, 汪柯, 程凯凯, 潘孝 晨, 孙耿. 不同土壤耕作模式对双季水稻生理特性与产量的 影响. 作物学报, 2019, 45: 740-754.

Tang H M, Xiao X P, Li C, Tang W G, Guo L J, Wang K, Cheng K K, Pan X C, Sun G. Effects of different soil tillage systems on physiological characteristics and yield of double-cropping rice. Acta Agron Sin, 2019, 45: 740-754 (in Chinese with English abstract).

[28] Page K L, Allen D E, Dalal R C, Slattery W. Processes and magnitude of $\mathrm{CO}_{2}, \mathrm{CH}_{4}$ and $\mathrm{N}_{2} \mathrm{O}$ fluxes from liming of Australian acidic soils: a review. Aust J Soil Res, 2009, 47: 747-762.

[29] Kumar M, Kundu D K, Ghorai A K, Mitra S, Singh S R. Carbon and nitrogen mineralization kinetics as influenced by diversified cropping systems and residue incorporation in inceptisols of eastern Indo-Gangetic Plain. Soil Tillage Res, 2018, 178: 108-117.

[30] 侯文峰, 李小坤, 王思潮, 汪金平, 徐祥玉, 熊又升, 丛日环. 石灰与秸秆配施对冷浸田水稻产量与土壤特性的影响. 华中 农业大学学报, 2015, 34(5): 58-62.

Hou W F, Li X K, Wang S C, Wang J P, Xu X Y, Xiong Y S, Cong R H. Effects of combined application of lime and straw on rice yield and soil properties in cold waterlogged paddy field. $J$ Huazhong Agric Univ, 2015, 34(5): 58-62 (in Chinese with English abstract).

[31] 曾廷廷, 蔡泽江, 王小利, 梁文君, 周世伟, 徐明岗. 酸性土 壤施用石灰提高作物产量的整合分析. 中国农业科学, 2017, 50: 2519-2527.

Zeng T T, Cai Z J, Wang X L, Liang W J, Zhou S W, Xu M G. Integrated analysis of liming for increasing crop yield in acidic soils. Sci Agric Sin, 2017, 50: 2519-2527 (in Chinese with English abstract).

[32] Li Y, Cui S, Chang S X, Zhang Q Q. Liming effects on soil pH and crop yield depend on lime material type, application method and rate, and crop species: a global meta-analysis. J Soil Sediment, 2019, 19: 1393-1406. 